\title{
Large-eddy simulation study of thermally stratified canopy flow
}

\author{
Bastian Nebenführ · Lars Davidson
}

Received: August 2014 / Accepted: 10 March 2015

\begin{abstract}
A number of large-eddy simulations (LES) are performed for the calculation of the airflow over a horizontally homogeneous forest canopy for a wide range of thermal stability classes. For the first time, results from LES of a stably stratified canopy are also presented. Simulation results compare favourably to recent field measurements over a pine forest in south-eastern Sweden. The simple heat source model was found to perform adequately and to yield within-canopy heat-flux profiles typically observed for stable conditions in the field. Evidence was found for a layer of unstably stratified air in the canopy trunk space under stable stratification. The importance of a secondary wind-speed maximum is emphasized in stable conditions. Examination of the budget equation of turbulent kinetic energy (TKE) revealed, that during stable stratification, pressure transport plays an increasingly important role in supplying the canopy region with TKE.
\end{abstract}

Keywords Atmospheric boundary layer · Forest canopy · Forest turbulence · Large-eddy simulation - Thermal stratification - Turbulent kinetic energy budget

\section{Introduction}

Knowledge about the flow field, the turbulence structure and the exchange processes in and above forest canopies is of interest for a wide range of applications, such as, for example, the exchange of greenhouse gases between forests and the atmosphere, possible wind damage and wind throw at forest edges, the spreading of wild fires, and the dispersion of pollen and pollutants. Moreover, the implications of forest turbulence on the fatigue loads of wind turbines have recently prompted significant research activity (Bergström et al. 2013; Nebenführ and Davidson 2014; Arnqvist et al. 2014; Nebenführ et al. 2014).

Turbulence in and above canopies has been characterized in field measurements (e.g. Allen Jr 1968; Cionco 1972; Finnigan 1979; Baldocchi and Meyers 1988; Högström et al.

B. Nebenführ $(\bigotimes) \cdot$ L. Davidson

Department of Applied Mechanics, Chalmers University of Technology, Gothenburg, Sweden

E-mail: basneb@chalmers.se

B. Nebenführ · L. Davidson

Swedish Wind Power Technology Centre (SWPTC) 
1989; Amiro 1990; Kruijt et al. 2000; Launiainen et al. 2007; Dupont and Patton 2012) and in wind-tunnel models and observations (e.g. Raupach et al. 1986; Brunet et al. 1994; Novak et al. 2000; Poggi et al. 2004b; Segalini et al. 2013). Lately, numerical simulations, and in particular large-eddy simulations (LES), have become increasingly applied to canopy flows. Disregarding the effects of the flexibility of trees and neglecting the individual canopy elements, it is possible to describe a forest canopy in terms of the leaf-area density; in such an approach, the forest is simply represented as the drag force exerted by the trees on the airflow. This makes it possible to integrate forest canopies explicitly into the simulation domain of a LES and therefore to simulate the flows both above and within the canopy, together with their interactions.

Shaw and Schumann (1992) performed LES explicitly with a forest canopy, and they simulated a $20 \mathrm{~m}$-high forest under neutral and weakly unstable conditions using a fairly fine grid on a very limited domain, stretching only up to three canopy heights above the ground. Later, Shaw and Patton (2003) attempted to refine the forest model by also taking into account skin friction of the canopy elements. They further included a passive transport equation for wake scale turbulence, which was found to not significantly influence the simulations.

The effect of the vertical leaf-area density profile in horizontally homogeneous forests has been explored by Dupont and Brunet (2008b) and Huang et al. (2009). Raupach et al. (1996) established the widely accepted mixing-layer analogy for canopy flows, and proposed that canopy flows behave similarly to a plane mixing layer at the canopy top. This analogy is only valid for sufficiently dense canopies as indicated by, for example, Novak et al. (2000) and Dupont and Brunet (2008b). Sparse canopies have been shown to behave similarly to a rough wall turbulent boundary layer, and Huang et al. (2009) investigated the transition between the two regimes by gradually increasing the vertical canopy density in their simulations.

Also horizontally heterogeneous forests, such as those with a clearing-forest-clearing type of pattern (Dupont and Brunet 2008a; Dupont et al. 2011) or with flow passing over a canopy edge (e.g. Yang et al. 2006b; Cassiani et al. 2008; Dupont and Brunet 2009), have gained much attention. Canopies organized in rows were recently investigated in association with the flow through a vineyard (Bailey and Stoll 2013; Chahine et al. 2014), while results for the simulation and recognition of coherent turbulent structures above canopies can be found in Kanda and Hino (1994), Watanabe (2004), Dupont and Brunet (2009), Finnigan et al. (2009).

Recently, realistic features have been considered in the simulation of canopy flow, such as the representation of actual plants (Yue et al. 2007a,b; Bailey and Stoll 2013), arbitrary canopy heterogeneity (Bohrer et al. 2009) and canopy densities determined from terrestrial laser scanning data (Schlegel et al. 2012). Detailed inclusion of a number of single trees has been the focus of Endalew et al. (2009) and Schröttle and Dörnbrack (2013), who used two and 16 trees, respectively. As opposed to the common approach of simply representing the forest in terms of a drag force, Chatziefstratiou et al. (2014) explicitly also included the effect of flow restriction due to plants taking up some part of the computational cell.

Most research to date has been focused on neutrally stratified conditions, although unstable stratification was considered by Shaw and Schumann (1992), Dwyer et al. (1997), Shen and Leclerc (1997) and Bohrer et al. (2009). To our knowledge, stable atmospheric conditions over a forest have not yet been subject to investigation. Hu et al. (2002) used a two-dimensional simulation technique to capture wave-like motions during nighttime, treating the temperature field as a passive scalar. 
In contrast, the atmosphere is rarely neutral and therefore most experiments include stratification effects. Shaw et al. (1988) concentrated on the influence of stability on basic turbulence properties, and found a considerable decrease of the canopy drag coefficient with the onset of stable stratification. Moreover, they found that under stable stratification, momentum transfer deep into the canopy is less efficient than under neutral or unstable stratification. Baldocchi and Meyers (1988) investigated flow over and through a deciduous forest and found considerable differences between night and day for the turbulence statistics. Second- and third-order turbulence statistics were studied in Leclerc et al. $(1990,1991)$ in a deciduous forest, while Kruijt et al. (2000) examined turbulence statistics in two Amazon rain forests. The influence of stratification on length scales was examined by Brunet and Irvine (2000) for several different sites. Villani et al. (2003) presented measurements over a northern hardwood forest and Launiainen et al. (2007) used measurements in a pine forest for a range of four stability classes. The effect of thermal stability on the mean flow and the turbulence statistics inside a hardwood forest was explored by $\mathrm{Su}$ et al. (2008). Most recently Dupont and Patton (2012) summarized results from the CHATS experiment related to flow over an orchard.

Here, LES is used to investigate the flow over a horizontally homogeneous forest, and comparison is made with recent field measurements in a pine forest in the south-east of Sweden (Bergström et al. 2013; Arnqvist et al. 2014). Six atmospheric stability classes, ranging from unstable through neutral to very stable conditions, were covered in the field measurements. Here, LES are carried out for each of the six stability classes. Firstly, simulations are tested for all stability classes against the measurements, then the influence of thermal stratification on the flow inside and above the canopy is investigated. For that purpose, we use common turbulence parameters, first-, second- and higher-order moments of turbulence and the budget of turbulent kinetic energy (TKE).

\section{Material and methods}

\subsection{Governing equations}

In LES, the turbulent eddies include the large, resolvable scales and small, subgrid scales (SGS), the latter needing some kind of parametrization. This distinction is done implicitly by the grid and is usually referred to as grid filtering. Here, the incompressible, grid-filtered Navier-Stokes equations and a transport equation for the potential temperature are solved,

$$
\begin{gathered}
\frac{\partial \bar{u}_{i}}{\partial x_{i}}=0, \\
\frac{\partial \bar{u}_{i}}{\partial t}+\frac{\partial\left(\bar{u}_{i} \bar{u}_{j}\right)}{\partial x_{j}}=-\frac{1}{\rho} \frac{\partial \bar{p}}{\partial x_{i}}+\frac{\partial}{\partial x_{j}}\left(v \frac{\partial \bar{u}_{i}}{\partial x_{j}}-\tau_{i j}\right) \\
+\frac{g}{\theta_{0}} \theta^{\prime \prime} \delta_{i 3}+F_{f, i}+F_{c, i}, \\
\frac{\partial \bar{\theta}}{\partial t}+\frac{\partial\left(\bar{\theta} \bar{u}_{j}\right)}{\partial x_{j}}=\frac{\partial}{\partial x_{j}}\left(\frac{v}{\operatorname{Pr}} \frac{\partial \bar{\theta}}{\partial x_{j}}-\tau_{i \theta}\right)+S_{h},
\end{gathered}
$$

where $\bar{u}_{i}$ is the velocity component in the $x_{i}$-direction $\left(\bar{u}_{1}=\bar{u}, \bar{u}_{2}=\bar{v}, \bar{u}_{3}=\bar{w}\right), \rho$ is the air density, $\bar{p}$ is the pressure, $g$ is the acceleration due to gravity, $\bar{\theta}$ and $\theta_{0}$ are the potential and the reference temperature, respectively, $v$ is the kinematic viscosity, $\operatorname{Pr}=0.72$ is the Prandtl number, $\delta_{i 3}$ is the Kronecker delta and the double primes indicate a deviation from 
the horizontal mean. Grid-filtered quantities are denoted by overbars. In Eq. 1b, $F_{f, i}$ and $F_{c, i}$ are the forces caused by the forest drag and the Coriolis effect, respectively, while the term $S_{h}$ in Eq. 1c denotes the vertically distributed forest heat source. The terms $F_{f, i}$ and $F_{c, i}$ are,

$$
\begin{aligned}
& F_{f, i}=-C_{D} a_{f} U \bar{u}_{i}, \\
& F_{c, i}=2 \Omega \sin (\phi)\left(\bar{u}_{j}-u_{j, g}\right) \varepsilon_{i j 3},
\end{aligned}
$$

where $C_{D}$ denotes the forest drag coefficient equal to 0.15 (Shaw et al. 1988), $a_{f}$ is the vertical leaf-area density of the forest, $U$ is the local wind speed, $\Omega$ is the Earth's rotation rate, $\phi$ is the latitude (here taken as $57^{\circ} \mathrm{N}$, which corresponds to the latitude of the field measurement site in Ryningsnäs), $u_{j, g}$ is the geostrophic wind component and $\varepsilon_{i j 3}$ is the alternating unit tensor. Even though Shaw et al. (1988) demonstrated that $C_{D}$ decreases in stable conditions, a constant value is used here for simplicity.

The effect of stratification is modelled following Shaw and Schumann (1992), where we assume that the forest is heated through solar radiation and that the air in contact with the leaves in turn is heated through heat conduction. For the sake of simplicity, we neglect the effect of heat radiation from the forest. Furthermore, the ground surface is taken to be an adiabatic wall, which implies that there is no heat to warm the ground. The strength of the source is proportional to the amount of solar radiation absorbed by the vegetation. Consequently, the heat source is strongest in the upper region of the forest and diminishes with increasing depth into the canopy. The canopy heat source term reads,

$$
S_{h}=\frac{\partial Q(z)}{\partial z}=\frac{\partial}{\partial z}\left(Q_{h} \exp \left(-\gamma A_{c}\right)\right)
$$

where $\gamma=0.6$ is the extinction coefficient of light (Shaw and Schumann 1992), $Q(z)$ and $Q_{h}$ are the heat-flux profile and the canopy-top heat flux value, respectively, and $A_{c}$ is the downward cumulative leaf-area index (LAI), defined as

$$
A_{c}=\int_{z}^{h} a_{f} d z
$$

with $h$ being the canopy height. The heat flux is modelled in the same way for unstable and stable conditions (with opposing signs, due to opposite signs on $Q_{h}$ ). Note that it is not obvious that the forest heat source should be modelled in the same way in stable and unstable conditions, since during nighttime, when the stable boundary layer evolves, heat transfer is mostly governed by longwave radiation as pointed out, for example, by Garratt (1992). Measurements, however, indicate that indeed the heat flux inside the canopy shows the largest magnitude at the canopy top in both stable and unstable stratification (Kaimal and Finnigan 1994; Cava et al. 2006; Dupont and Patton 2012).

The effect of humidity is neglected in the present study, since we consider an idealized situation due to the use of a horizontally homogeneous forest and periodic boundary conditions. It is, however, acknowledged that the influence of humidity may not be negligible on the flow above a transpiring forest canopy.

It should be noted that Eq. $1 \mathrm{c}$ is only solved for non-neutral conditions, i.e. if $Q_{h} \neq 0$. In (1b) and (1c), $\tau_{i j}$ and $\tau_{i \theta}$ are the subgrid-scale stress and heat flux, respectively, where these 
are modelled as,

$$
\begin{aligned}
\tau_{i j} & =-v_{t}\left(\frac{\partial \bar{u}_{i}}{\partial x_{j}}+\frac{\partial \bar{u}_{j}}{\partial x_{i}}\right), \\
\tau_{i \theta} & =-v_{h} \frac{\partial \bar{\theta}}{\partial x_{i}} .
\end{aligned}
$$

A SGS model solving the transport equation for subgrid-scale TKE, $k$, similar to that proposed by Deardorff (1980), is used to compute the eddy viscosity, $v_{t}$, and the eddy diffusivity of heat, $v_{h}$. In the following, this model is referred to as the $k$-equation model. Several previous studies have employed that SGS model for numerical studies of the atmospheric boundary layer (ABL) (e.g. Moeng 1984; Kanda and Hino 1994; Jiménez and Cuxart 2005) and canopy flows (e.g. Dwyer et al. 1997; Shaw and Patton 2003; Bohrer et al. 2009). The transport equation for $k$ is given by,

$$
\begin{aligned}
\frac{\partial k}{\partial t}+\frac{\partial\left(k \bar{u}_{j}\right)}{\partial x_{j}} & =-\tau_{i j} \frac{\partial \bar{u}_{i}}{\partial x_{j}}+\frac{\partial}{\partial x_{j}}\left(\left[v+\frac{v_{t}}{\sigma_{k}}\right] \frac{\partial k}{\partial x_{j}}\right) \\
& -\frac{g}{\theta_{0}} \tau_{i \theta} \delta_{i 3}-\varepsilon-\frac{8}{3} C_{D} a_{f} U \bar{u}_{i} k,
\end{aligned}
$$

where $\varepsilon$ is the dissipation rate of SGS turbulent kinetic energy and $\sigma_{k}=1$. We account for the destruction of TKE through forest drag with the help of the last term on the right-hand side (Shaw and Patton 2003).

The eddy viscosity, necessary for the parametrization of the SGS stress in Eq. 6, is computed as the product of a length scale, $l$, and a velocity scale, $\sqrt{k}$, viz.

$$
v_{t}=0.1 \sqrt{k} l \text {. }
$$

To allow for a reduction in the turbulent length scale in stable conditions, the length scale is computed as

$$
l=\min \left(0.76 \sqrt{k}\left(\frac{g}{\theta_{0}} \frac{\partial \bar{\theta}}{\partial z}\right)^{-1 / 2}, \quad \Delta_{s}\right)
$$

whenever $\partial \bar{\theta} / \partial z>0$. In Eq. $10, \Delta_{s}=\left(\Delta_{x} \Delta_{y} \Delta_{z}\right)^{1 / 3}$ is the cubic root of the grid volume and the classical length scale used in LES. The SGS heat flux from Eq. 7 is then parametrized by defining $v_{h}$ as

$$
v_{h}=\left(1+2 l / \Delta_{s}\right) v_{t} .
$$

Finally, the dissipation rate, $\varepsilon$, is modelled as (Deardorff 1980),

$$
\varepsilon=\left(0.19+0.51 l / \Delta_{s}\right) \frac{k^{3 / 2}}{l} .
$$

\subsection{Experimental data}

In the framework of the Swedish project "Vindforsk" (Bergström et al. 2013), extensive measurements were carried out in a forested region near Ryningsnäs in the south-east of Sweden. A 138-m tall meteorological mast, placed on the north-western corner of a roughly $200 \times 250 \mathrm{~m}^{2}$ clearing, was used for the measurements. The measurement campaign took place from November 2010 until February 2012. As reported in Bergström et al. (2013), Arnqvist et al. (2014) and Chougule et al. (2015), the average forest height near the mast was 
approximately $20 \mathrm{~m}$ and the forest consisted predominantly of Scots pine (Pinus silvestris). The mast was equipped with measurement booms at heights $z / h \approx 2,3,4,5,6,7$. As the measurement mast is placed on the edge of a clearing, no measurement was possible inside the canopy and thus the lowest measurements were taken at $z / h \approx 2$. Only data from the western sector are considered here, since in that direction, the landscape is mainly covered with forest. Additionally, the influence of two wind turbines to the south and north-east of the measurement mast was mitigated.

In the experiments, six different stability classes ranging from unstable to very stable atmospheric conditions were identified based on the stability parameter $h / L$, with $L$ being the Obukhov length, defined as

$$
L=-\frac{u_{*}^{3} \theta_{0}}{\kappa g Q_{h}},
$$

where $u_{*}$ is the friction velocity, that is defined later and $\kappa=0.41$ denotes the von Kármán constant.

Table 1 gives an overview over the stability classes and the range of the stability parameter used for distinction. All the experimental data represent mean values of a number of datasets, which were averaged upon identification for a certain stability class. One dataset corresponds to the temporal average of a 30-min time history. The number, $N$, of datasets used in each stability class are also given in Table 1, where it can be seen that the majority of the datasets are in the neutral or stable regimes. Detailed information and analysis of the measurements can be found in the final project report (Bergström et al. 2013) and in the study of Arnqvist et al. (2014).

Table 1: The different stability classes. Also the range of the stability parameter $h / L$ applicable for each class and the total number of datasets are indicated. $Q_{h}$ is the canopy-top heat flux used in the simulation of the respective stability class.

\begin{tabular}{|c|c|c|c|c|}
\hline Class & Description & $h / L$ range & $\bar{N}$ & $Q_{h}\left[\mathrm{~K} \mathrm{~m} \mathrm{~s}^{-1}\right]$ \\
\hline K1 & Unstable & $-0.2<L<-0.05$ & 53 & 0.015 \\
\hline $\mathrm{K} 2$ & Unstable, near-neutral & $-0.05<L<-0.02$ & 94 & 0.01 \\
\hline K3 & Neutral & $0<|L|<0.02$ & 861 & 0.0 \\
\hline K4 & Stable, near-neutral & $0.02<L<0.05$ & 367 & -0.0035 \\
\hline K5 & Stable & $0.05<L<0.2$ & 369 & -0.005 \\
\hline K6 & Very stable & $0.2<L$ & 206 & -0.0075 \\
\hline
\end{tabular}

\subsection{Simulation set-up}

The simulations are performed on a rectangular domain with a vertical height of $H=400$ $\mathrm{m}$. A right-handed coordinate system is used, where coordinates $x, y$ and $z$ relate to the streamwise, lateral and vertical directions, respectively, and the computational domain has dimensions $\left(x_{\max }, y_{\max }, z_{\max }\right)=(4 H, 2 H, H)$. A grid with $\left(n_{x}, n_{y}, n_{z}\right)=(192,96,48)$ cells is used to discretize the computational domain, with the grid spacing constant in the horizontal directions ( $x$ and $y$ ). The forest density varies with height, as depicted in Fig. 1, but is assumed to be homogeneous in the horizontal directions. As in the experiments, a canopy height of $h=20 \mathrm{~m}$ is used in the simulations throughout. 10 grid cells are used to discretize the canopy in the vertical direction, yielding a constant grid spacing of $\Delta_{z}=2 \mathrm{~m}$ inside the 
forest. Above the forest, the cells are geometrically stretched by $7.5 \%$. The geostrophic wind is set to $\left(u_{g}, v_{g}\right)=(5,0) \mathrm{m} \mathrm{s}^{-1}$ in all cases, and a potential temperature profile with constant temperature $300 \mathrm{~K}$ is initially prescribed. A constant timestep of $\Delta_{t}=0.4 \mathrm{~s}$ is used in all simulations in order to ensure that the Courant number is below 0.25 in the entire domain.

All simulations have an initial "start-up phase", in which the temperature profile adjusts to the applied heating/cooling and the wind turning with height can adapt to its fully developed state. The length of the start-up is highly dependent on the thermal stratification, and while the flow develops rather quickly in unstable or neutral conditions, a large number of timesteps is necessary in stable conditions. In all cases, the start-up phase is long enough to ensure fully-developed flow. All quantities shown below are averaged both in time and space (in the horizontal direction), with temporal averaging carried out for 30000 timesteps.

At the ground, the momentum flux is specified from standard similarity theory; the horizontally averaged local wind speed, $U_{p a r}=\left\langle\sqrt{\bar{u}^{2}+\bar{v}^{2}}\right\rangle$, at the first vertical grid point, $\Delta_{z} / 2$, is used for evaluation of the surface momentum flux, viz

$$
\tau_{i 3, w}=-\left[\frac{U_{p a r} \kappa}{\ln \left[\left(\Delta_{z} / 2\right) / z_{0}\right]}\right]^{2} \frac{\bar{u}_{i}\left(x, y, \Delta_{z} / 2\right)}{U_{p a r}},(i=1,2),
$$

where $z_{0}=0.001 h$ is the roughness length according to Shaw and Schumann (1992). The top of the domain is treated as a rigid, frictionless lid. Periodic boundary conditions are employed in the $x$ - and $y$-directions. The use of periodic boundary conditions and the addition (subtraction) of heat through the forest leads to an ever increasing (decreasing) absolute temperature in the simulation. We are not interested in the absolute temperature here, and none of our equations depends on the absolute temperature; hence, the absence of a balance in the heat equation is not expected to have any effect on the outcome of our simulation.

As mentioned above, at Ryningsnäs, the forest mainly consists of Scots pine, which we model with the help of the empirical model of Lalic and Mihailovic (2004). Figure 1 shows the resulting leaf-area density profile, resembling a tree with a more dense crown region and a rather sparse trunk space. The profile has a leaf-area index of $A=\int_{0}^{h} a_{f} d z \approx 4.3$, where, according to the review of Breuer et al. (2003), the leaf-area index of Scots pine trees varies between 1.1 and 7.2, with a mean value of 3.8.

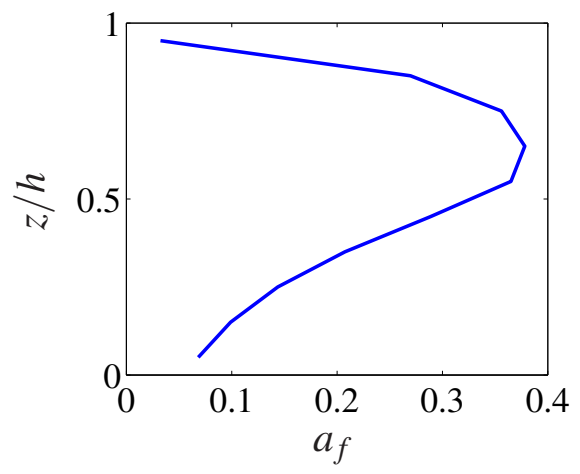

Fig. 1: Leaf-area density profile of the modelled forest, as defined in Eq. 2.

A coordinate transformation to a local coordinate system is applied for all of the quantities presented in this study. This is done in order to account for the wind turning induced 
by the Coriolis effect. In line with common meteorological practice, the $x$-axis of the local coordinate system is aligned with the mean wind direction at every height and the $z$-axis is vertically upwards. Quantities defined in the local coordinate system are denoted with subscript " $"$ ".

\section{Validation against measurements}

In order to validate our simulations, a comparison is made with measurements. In all the plots, the upper end of the canopy is marked by the horizontal dashed line. The variability of the measurements is given as $\pm \sigma$ (standard deviation), where available. Figure 2 displays the horizontal wind speed, $U_{\ell}=\left(\bar{u}^{2}+\bar{v}^{2}\right)^{1 / 2}$, for all six stability classes. In accordance with the measurements, the wind-speed profiles are normalized with the friction velocity $u_{*}=$ $\left[\left\langle u^{\prime} w^{\prime}\right\rangle_{\ell}^{2}+\left\langle v^{\prime} w^{\prime}\right\rangle_{\ell}^{2}\right]^{1 / 4}$ evaluated at $z / h=2$. At first glance, a good agreement of simulations with measurements can be observed for all six cases. For all numerical cases, the typical features of the wind-speed profile for a canopy flow are obtained. The strong reduction in wind speed inside the canopy and the inflection point at the top of the canopy are clearly visible. Cases K1 and K2 do not capture the correct curvature of the of the wind-speed profile, which indicates overly strong mixing due to buoyancy.

Since no measurement is available for the levels inside the canopy, we cannot validate our simulations for that region. However, our simulations show behaviour in line with results commonly available from numerical studies (e.g. Shaw and Schumann 1992; Dupont and Brunet 2008b; Bohrer et al. 2009) and measurements (e.g. Baldocchi and Meyers 1988; Finnigan 2000; Dupont and Patton 2012), which gives confidence that our model also performs satisfactory inside the canopy.

Wind turning with height can be considerable and is shown in Fig. 3. To be consistent with the measurements, the change at each height relative to the wind direction at $z / h=2$ is depicted. For the unstable cases, LES predicts the wind turning to be smaller than the measurements. In the simulations, this is caused by the enhanced mixing due to buoyancy. Consequently, the turbulence intensity increases and the wind speed is reduced, making the Coriolis effect less significant for these two cases. Both under neutral and stable conditions, the simulated turning is in better agreement with measurements. It should be noted that (Bergström et al. 2013) have argued that the measurements may show wind turning that is too high, and is caused by internal twisting of the measurement tower. Furthermore, it can be observed that the predicted wind turning is considerable inside the forest. Dupont and Brunet (2008b) also found strong wind turning inside the canopy, regardless of the leaf-area density distribution, in their numerical study. The wind turning inside the forest is only indirectly due to the Coriolis force. As will become clear from Fig. 4, the vertical momentum flux diminishes due to the presence of the forest and the wind direction is determined by the large-scale pressure gradient, and hence, the geostrophic wind (Dupont and Brunet 2008b).

The vertical momentum flux in the streamwise direction is examined, where good agreement with the measurements is achieved (see Fig. 4). For all six stability classes, the peak in the momentum flux is located at the top of the canopy, where the largest wind shear can be found (compare with Fig. 2). From the peak at the canopy top, the momentum flux decreases linearly with height to zero. It should be noted that no constant stress layer is visible here due to the scale of the vertical axis in the presented plots. A close-up of the canopy and the roughness sublayer would reveal the near-constant behaviour of the momentum flux (not shown). In the first four cases, the height of the boundary layer is greater than the height of the computational domain, and the momentum flux is forced to be zero at the top of the do- 
main by the rigid boundary condition used. It would be interesting to explore the influence of the location of the upper boundary on the simulation results, in particular for the two unstable cases. However, this issue is left to future studies. For the stable and very stable cases, the momentum flux goes to zero well below the top of the domain, implying that the entire ABL is simulated in the LES.

The variances in the wind-speed components, normalized by $u_{*}^{2}$, are presented in Fig. 5 . In general, the streamwise variances are the largest and the vertical variances are the smallest with the lateral variance lying between the two. However, for the very stable and unstable cases, the measurements suggest that the streamwise and lateral variances are of roughly the same magnitude. Since the presence of the ground dampens vertical turbulence motions, the vertical variance assumes the smallest values. The streamwise variance seems well predicted for the neutral and the slightly stable case, however, the variance near the forest appears overpredicted in those cases. In contrast, the variances of the lateral and the vertical velocity components are underpredicted in all simulations. In the vertical direction this underprediction is most pronounced in the roughness sublayer, indicating that the simulations do not predict sufficiently high values of resolved turbulent kinetic energy. The effect proves to be most severe in the unstably stratified cases. Increasing the domain height in order to capture more large-scale, energy-containing turbulent motions may help to mitigate this deficiency. Other possible solutions may be to increase the grid resolution in the horizontal directions or to include the effect of energy backscatter (e.g. Bhushan and Warsi 2005; Bhushan et al. 2006; Davidson 2009) in the SGS model. It is noteworty that in the very stable case, the variances show a sudden increase at $z \approx 8$. This happens at heights above the ABL height, where the flow is laminar, and consequently, the $k$-equation model yields very small values of eddy viscosity, leading to numerical oscillations. Hence, the $k$-equation SGS model does not perform well in increasingly stable conditions. However, recently, a new tuningfree scale-dependent dynamic SGS models has emerged (Porté-Agel et al. 2000), and good performance in simulations of the stable ABL has been reported by Basu and Porté-Agel (2006), Kleissl et al. (2006) and Stoll and Porté-Agel (2008). Recently, the scale-dependent dynamics SGS model has been used for the simulation of a model canopy in a wind tunnel (Yue et al. 2008) and for the simulation of a vineyard canopy (Bailey and Stoll 2013).

The resolved skewness of the streamwise and vertical velocity components in the local coordinate system, $S k_{u, \ell}$ and $S k_{w, \ell}$, are depicted in Figs. 6 and 7, respectively. The measurements show streamwise skewnesses of nearly zero already from the first measurement point above the forest in all cases. One can observe that the measured behaviour is captured well, only for the two most stable simulations. Otherwise, the simulations predict the sign to change from positive to negative values at heights of $z / h \approx 2-z / h \approx 7$, depending on the thermal stability. This is probably a consequence of the rigid upper boundary condition. As no measurements are available inside the canopy, we rely on the body of literature for validation. Positive $S k_{u, \ell}$ inside the forest with decreasing values above have been frequently reported for LES (e.g. Shaw and Schumann 1992; Dupont and Brunet 2008b; Dupont et al. 2011) and observations (e.g. Baldocchi and Meyers 1988; Raupach et al. 1996; Dupont and Patton 2012; Segalini et al. 2013), which is in agreement with our results. The skewness of the vertical velocity is generally negative inside the forest and changes to positive values or vanishes above the forest as can be observed in Fig. 7. Here, our LES is able to capture the trends well in all cases. 


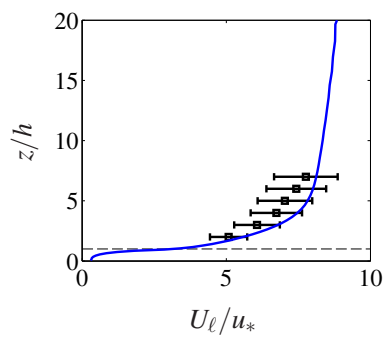

(a) unstable

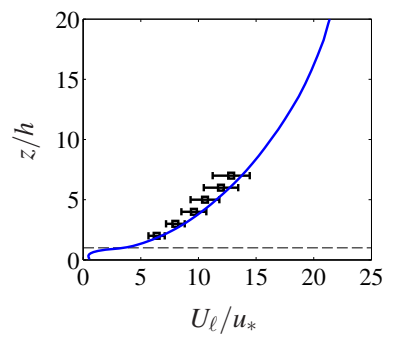

(d) slightly stable

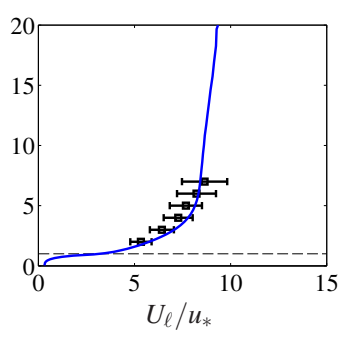

(b) slightly unstable

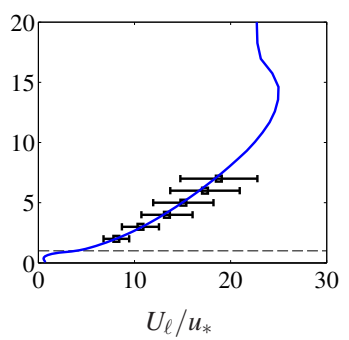

(e) stable

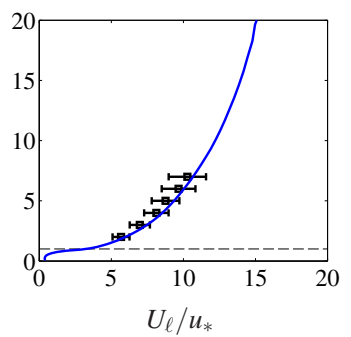

(c) neutral

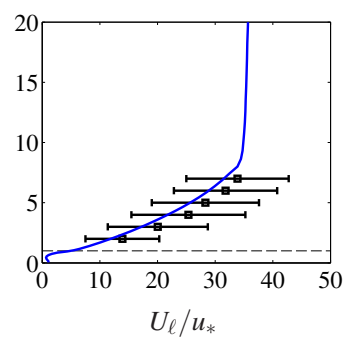

(f) very stable

Fig. 2: Horizontal wind speed profiles for the different stability classes. —- LES, $\square$ : Ryningsnäs measurements

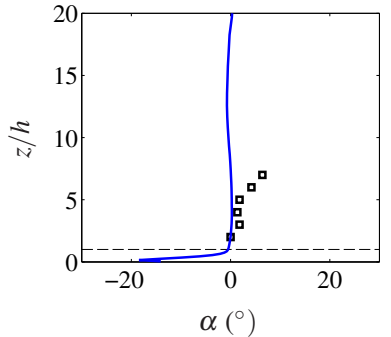

(a) unstable

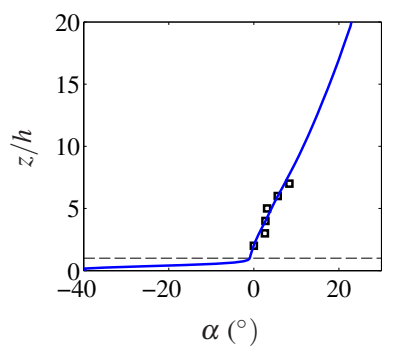

(d) slightly stable

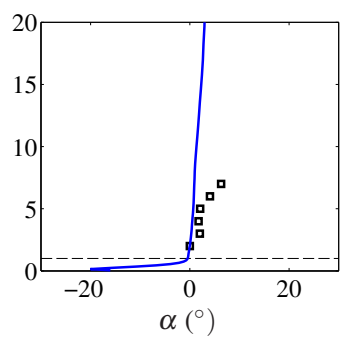

(b) slightly unstable

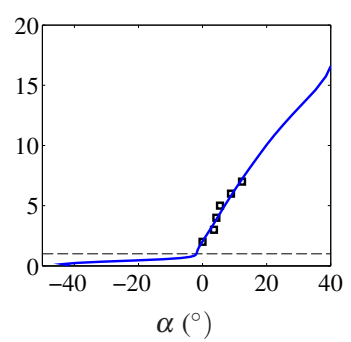

(e) stable

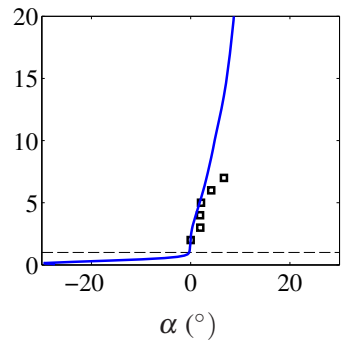

(c) neutral

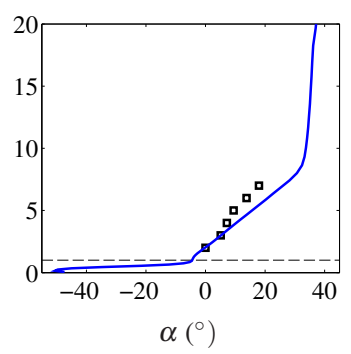

(f) very stable

Fig. 3: Wind turning angle in degrees, $\alpha-\alpha_{2 h}$, for the different stability classes.

LES,

$\square$ : Ryningsnäs measurements 


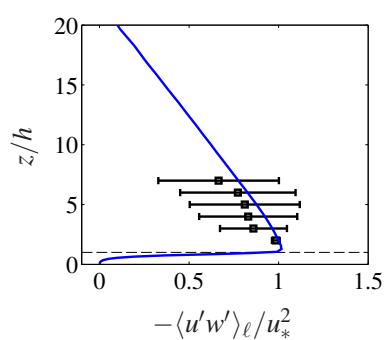

(a) unstable

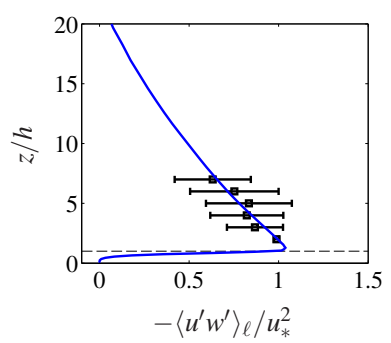

(d) slightly stable

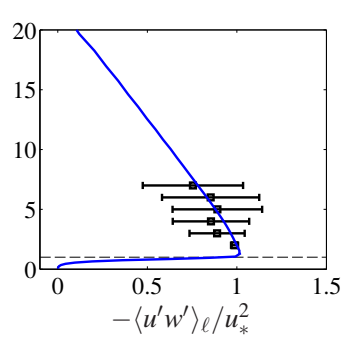

(b) slightly unstable

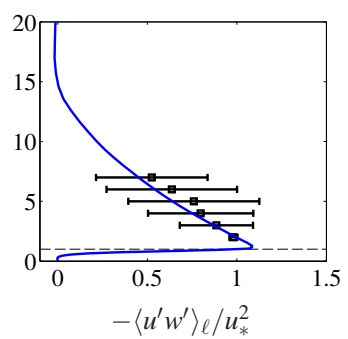

(e) stable

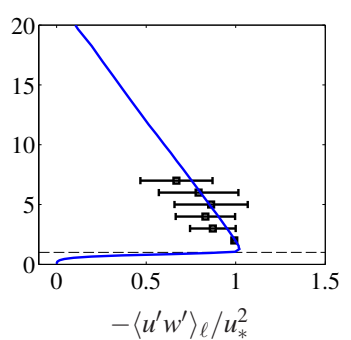

(c) neutral

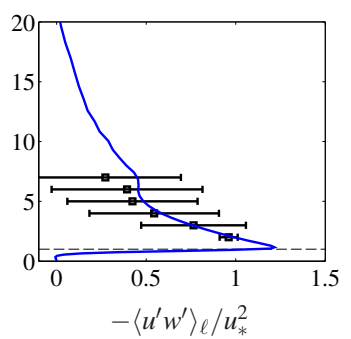

(f) very stable

Fig. 4: Resolved vertical momentum flux in the streamwise direction for the different stability classes. ——: LES, $\square$ : Ryningsnäs measurements

\section{Effect of thermal stratification}

In the following, the effect of thermal stratification on the canopy flow is studied for several typical quantities. Note, that from here on, the results from the very stable case (K6) are excluded, since the $k$-equation SGS model failed for this case and the results are therefore not to be trusted.

\subsection{Turbulence parameters}

One characteristic of canopy flow is the inflection point in the velocity profile at the canopy top, marking the location of the strongest wind shear. Often the so-called shear length scale, $L_{s}=U_{\ell}(h) /\left(\partial U_{\ell} / \partial z\right)_{h}$ is used to describe the wind shear (Raupach et al. 1996). The values calculated here range from $L_{s}=0.36 h$ to $L_{s}=0.33 h$ in unstable and stable conditions, respectively (see Table 2). Brunet and Irvine (2000) investigated the impact of stability on $L_{s} / h$ for six different measurement sites and found the shear length scale to decrease in stable conditions, while no clear trend was noticeable for unstable stratification. Consistent with our simulations, also Dupont and Patton (2012) report $L_{S} / h$ to gradually decrease in a deciduous orchard with increasingly stable conditions.

Buoyancy forces typically act to suppress turbulence in the stably stratified ABL, while for the unstable ABL turbulence is enhanced due to buoyant mixing. Table 2 gives the friction velocity obtained in the simulations for the different simulations, and as expected, compared to neutral conditions, the friction velocity increases and decreases for unstable and stable stratification, indicating enhanced and suppressed turbulence, respectively. 


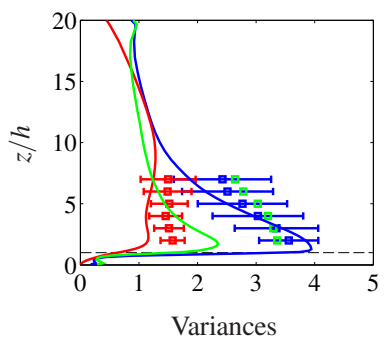

(a) unstable

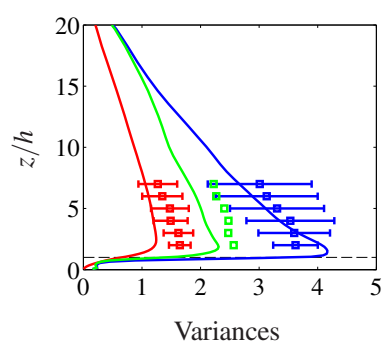

(d) slightly stable

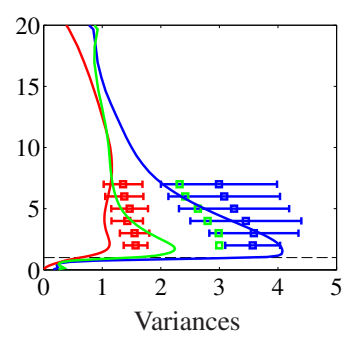

(b) slightly unstable

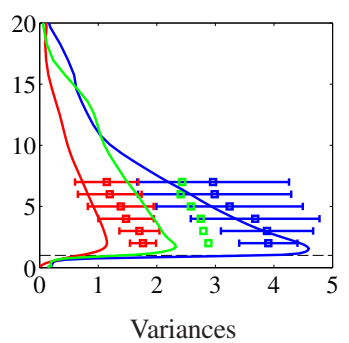

(e) stable

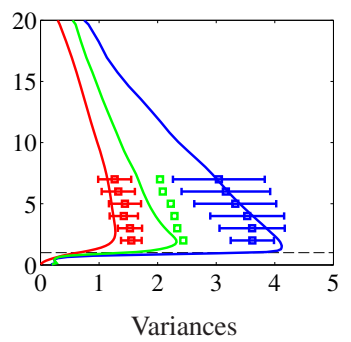

(c) neutral

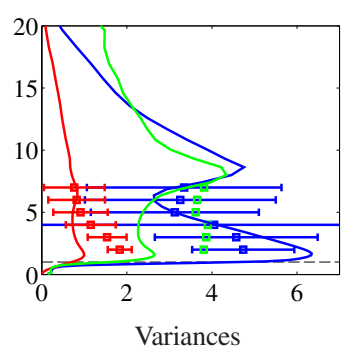

(f) very stable

Fig. 5: Resolved normalized variances of wind speed for the different stability classes. LES: - $:\left\langle u^{\prime} u^{\prime}\right\rangle_{\ell} / u_{*}^{2}, \longrightarrow:\left\langle v^{\prime} v^{\prime}\right\rangle_{\ell} / u_{*}^{2}, \longrightarrow:\left\langle w^{\prime} w^{\prime}\right\rangle_{\ell} / u_{*}^{2}$, Ryningsnäs measurements: $\square$ : $\left\langle u^{\prime} u^{\prime}\right\rangle_{\ell} / u_{*}^{2}, \square:\left\langle v^{\prime} v^{\prime}\right\rangle_{\ell} / u_{*}^{2}, \square:\left\langle w^{\prime} w^{\prime}\right\rangle_{\ell} / u_{*}^{2}$. The variability of the $v$ velocity variance is omitted for clarity.

The displacement height, $d$, of the forest was calculated using (Su et al. 2008)

$$
d=\frac{\int_{0}^{h} z\left(\partial\left\langle u^{\prime} w^{\prime}\right\rangle_{\ell} / \partial z\right) d z}{\int_{0}^{h}\left(\partial\left\langle u^{\prime} w^{\prime}\right\rangle_{\ell} / \partial z\right) d z}
$$

with values for the simulations given in Table 2. Only a minor increase in displacement height with increasing stability (from case $\mathrm{K} 1$ to $\mathrm{K} 5$ ) from values of $d=0.85 h$ to values of $d=0.86 h$ was found for the simulations. In the field measurements, the displacement height was estimated to be slightly lower with values of $0.75 h$ (Bergström et al. 2013), indicating that the simulated forest is more dense than the forest at the measurement site. An increasing displacement height under stable stratification suggests that the penetration depth of momentum into the canopy is reduced in these conditions. Even though thermal stratification has only a weak influence on $d$, the findings here indicate that the penetration depth of momentum into the canopy is reduced from unstable or neutral to stable conditions, which is in agreement with $\mathrm{Su}$ et al. (2008).

\subsection{First-order statistics}

In Fig. 8, the influence of thermal stratification on the wind speed is shown, where the wind speed is normalized with its value at the canopy top, $U_{\ell, h}$. It can be seen that the normalized 


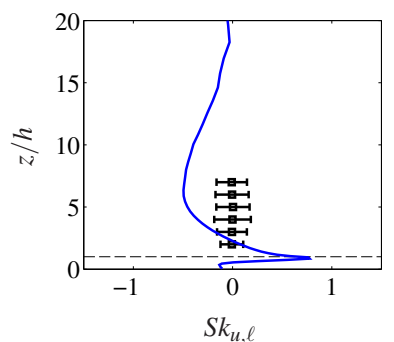

(a) unstable

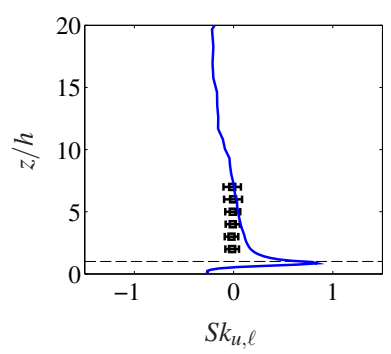

(d) slightly stable

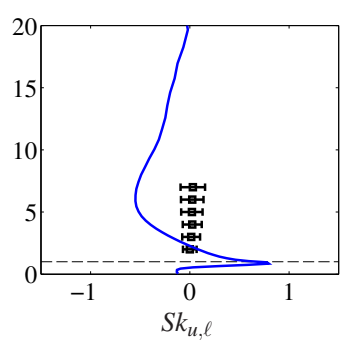

(b) slightly unstable

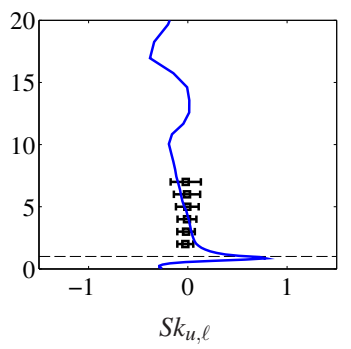

(e) stable

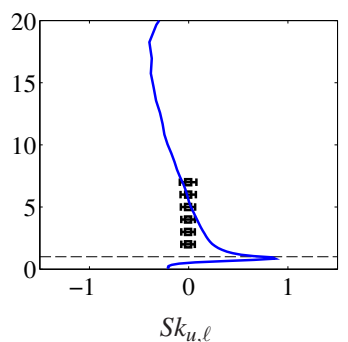

(c) neutral

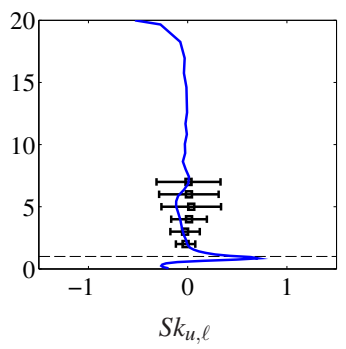

(f) very stable

Fig. 6: Resolved skewness of the streamwise velocity component for the different stability classes. — : LES, $\square$ : Ryningsnäs measurements

Table 2: Shear length scale $\left(L_{s} / h\right)$, friction velocity $\left(u_{*}\right)$, stability parameter $(h / L)$ and displacement height $(d / h)$ for the simulations.

\begin{tabular}{llccc}
\hline \hline Case & $L_{s} / h$ & $u_{*}\left[\mathrm{~m} \mathrm{~s}^{-1}\right]$ & $h / L$ & $d / h$ \\
\hline K1 & 0.361 & 0.415 & -0.056 & 0.853 \\
K2 & 0.357 & 0.405 & -0.040 & 0.854 \\
K3 & 0.344 & N/A & 0.854 \\
K4 & 0.353 & 0.271 & 0.047 & 0.858 \\
K5 & 0.342 & 0.224 & 0.120 & 0.863 \\
K6 $^{\text {a }}$ & 0.330 & 0.158 & 0.510 & 0.875 \\
\hline
\end{tabular}

${ }^{a}$ Values for the very stable case (K6) should be interpreted with caution and are excluded from the analysis hereafter.

wind speed increases with increasing stability, which is in line with observations in and above an orchard canopy (Dupont and Patton 2012).

Moreover, one can observe that for the unstably stratified simulations the normalized wind speed is not much influenced by the degree of instability. As will become clear later, these cases are completely dominated by thermal convection. For the stable case, a maximum in normalized wind speed can be seen at $z / h \approx 14$, often referred to as a low-level jet and being a phenomenon typically observed in the shallow nighttime boundary layer. Figure $8 \mathrm{~b}$ provides a closer view of the canopy region, where a secondary maximum in the wind speed close to the ground, caused by the relatively lower forest density in that region (see Fig. 1), can be identified (Shaw 1977). It is more pronounced in stable conditions, which is 


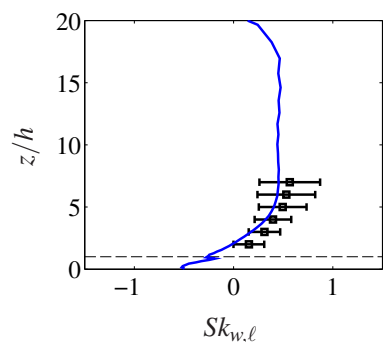

(a) unstable

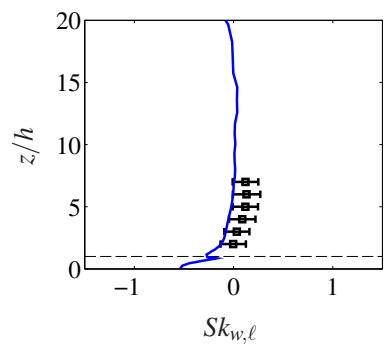

(d) slightly stable

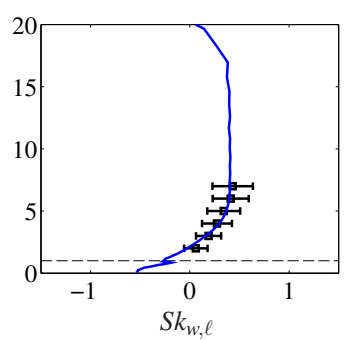

(b) slightly unstable

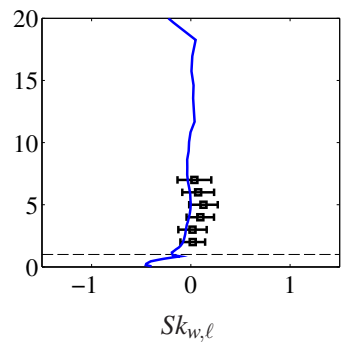

(e) stable

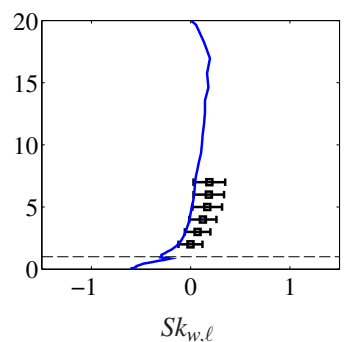

(c) neutral

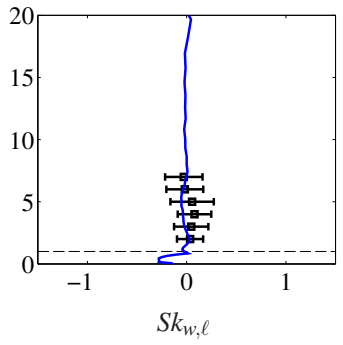

(f) very stable

Fig. 7: Resolved skewness of the vertical velocity component for the different stability classes. — : LES, $\square$ : Ryningsnäs measurements

consistent with the observations of Baldocchi and Meyers (1988), Launiainen et al. (2007) and Su et al. (2008).

\subsection{Second-order statistics}

The influence of thermal stratification on second-order statistical quantities is illustrated in Fig. 9. In stable conditions, the largest values of $\sigma_{u, \ell} / u_{*}$ for all simulations are obtained above the canopy, corresponding well with the measurements of Launiainen et al. (2007) in a homogeneous pine forest. Similarly to Arnqvist et al. (2014), we find that, above the forest, the streamwise component of turbulence is the weakest in unstable conditions. This can be explained by the increased importance of buoyancy fluctuations, acting in the vertical direction. Small, but not negligible, amounts of streamwise turbulence are found in the lower canopy at around $z \approx 0.15 h$ (see secondary maximum in Fig. 9a) with the vertical momentum flux being virtually zero at the same height, meaning that the turbulence at these levels is inactive in terms of vertical momentum transport (Finnigan 2000). This phenomenon has been observed in a number of field and wind-tunnel measurements (Finnigan 2000). We find this phenomenon to be most pronounced in unstable conditions, agreeing well with Launiainen et al. (2007), who found the inactive turbulence to increase slightly with unstable conditions. However, these authors found the largest amount of inactive turbulence for very stable conditions $(h / L>0.8)$.

The vertical momentum flux, depicted in Fig. 9c, normalized with $u_{*}^{2}$, does not change significantly for the unstable, neutral and near-neutral cases, which is in agreement with the 


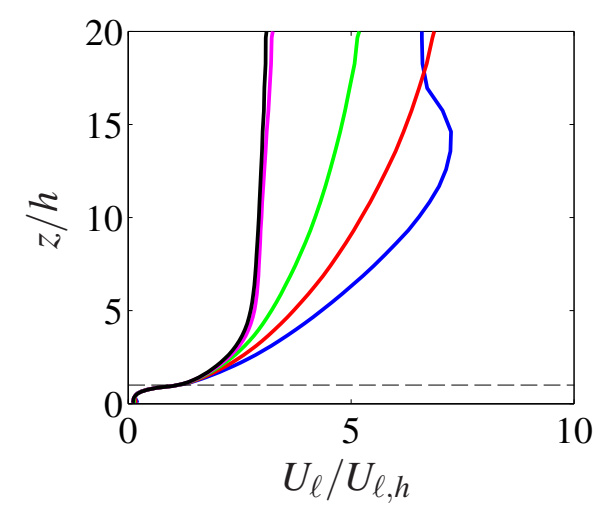

(a)

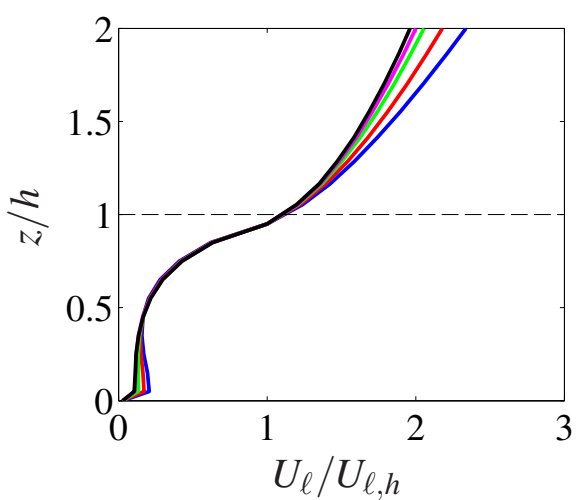

(b)

Fig. 8: Influence of thermal stratification on the normalized wind speed. Panel (b) provides a close-up view of the canopy region. $\longrightarrow$ : stable (K5), $\longrightarrow$ : slightly stable (K4), $\longrightarrow$ : neutral (K3), — : slightly unstable (K2), $\longrightarrow$ : unstable (K1).

findings of Dupont and Patton (2012), who report that the normalized momentum flux is not affected much by thermal stratification up to $z / h=3$. Inside the canopy, the momentum flux drops rapidly to very small values, indicating that the forest is quite efficient in absorbing the momentum flux. Regardless of stability, the magnitude of $\left\langle u^{\prime} w^{\prime}\right\rangle_{\ell}$ is reduced by more than $98 \%$ deep inside the forest $(z / h=0.25)$ from its value at $z / h=2$. Dupont et al. (2011) report a momentum flux reduction of more than $96 \%$ for their LES of a maritime pine forest, where the differences may be explained by the relatively less dense trunk space in their leaf-area density profile. Shaw et al. (1988) and Su et al. (2008) found that in stable conditions, the momentum flux is diminished more rapidly with depth into the canopy, implying a reduced penetration depth of momentum into the canopy under stable stratification, and the same trend can be observed here for the two stable cases.

Figure 9d shows the correlation coefficient, $R_{u w}=\left\langle u^{\prime} w^{\prime}\right\rangle_{\ell} / \sigma_{u, \ell} \sigma_{w, \ell}$, which is commonly understood as a measure of the efficiency of turbulent transport. Measurements presented in Shaw et al. (1988), Raupach et al. (1996) and Dupont and Patton (2012) indicate peak values of $R_{u w} \approx-0.5$, while LES of neutrally stratified forest flow has been reported to produce values of $R_{u w}=-0.6$ (Su et al. 1998). Our simulations predict the peak value at $z / h=0.85$ with magnitudes reaching up to $R_{u w} \approx-0.65$ in unstable conditions. A slight reduction in magnitude to $R_{u w} \approx-0.64$ can be seen for increasingly stable stratification, indicating slightly less efficient vertical momentum transfer in stable conditions. Inside the canopy, the influence of stable stratification becomes more obvious. While in neutral and unstable conditions, $R_{u w}$ shows a small magnitude near the ground, the onset of stability reduces this magnitude. In case $\mathrm{K} 5$, even a reversal of the sign of $R_{u w}$ is obtained at the height of the secondary wind maximum $(z / h \approx 0.2)$, which is associated with slightly positive values of $\left\langle u^{\prime} w^{\prime}\right\rangle_{\ell}$. Also Su et al. (2008) showed that $R_{u w}$ changed sign in the lower part of the canopy for their stable measurements.

The normalized vertical heat flux is analyzed in Fig. 9e for the within-canopy region. In order to preserve the sign of the heat flux, we use the magnitude of its canopy-top value for normalization. It can be seen that the heat flux reaches its largest magnitude shortly above 
the canopy, which is in good agreement with Dupont and Patton (2012). Above the forest, the heat flux remains almost constant as expected for the roughness sublayer. As demonstrated by Kaimal and Finnigan (1994), a positive heat flux may be encountered near the ground in stable stratification. Here, we find slightly positive heat fluxes in the lower canopy for the stable simulations, as shown in Fig. 9f, indicating the existence of a weak unstably stratified layer below the crowns of the trees. This unstably stratified layer is expected to become more significant with increasing overall stability.

\subsection{Higher-order statistics}

Here, the influence of thermal stratification on higher order statistics is presented. Launiainen et al. (2007) concluded from their measurements that the within-canopy skewness and kurtosis are rather insensitive to changes in stability. Contrasting results were obtained by Dupont and Patton (2012), who showed that both skewness and kurtosis decrease with stability inside the forest. Dupont and Patton (2012) stated moreover that under increasingly stable conditions, the flow changes from resembling a mixing layer to being similar to a regular rough-wall surface layer. It has also been found that the vertical skewness can become positive inside the forest in very stable conditions (Leclerc et al. 1991; Dupont and Patton 2012).

Figure 10 shows the skewness and kurtosis of the streamwise and vertical velocity components, respectively, and as mentioned in Sect. 3, the velocity components are skewed positively (streamwise component) and negatively (vertical component) inside the forest. Such a behaviour is consistent with measurements (Baldocchi and Meyers 1988; Amiro 1990; Lee and Black 1993; Raupach et al. 1996; Novak et al. 2000; Kruijt et al. 2000; Villani et al. 2003; Segalini et al. 2013) and simulations (Shaw and Schumann 1992; Su et al. 1998; Watanabe 2004; Dupont and Brunet 2008b) and suggests that mainly downward moving energetic gusts, the so-called sweeps, penetrate into the forest.

Above the canopy, $S k_{u, \ell}$ gradually reduces to zero, except for the unstable cases. For $\mathrm{K} 1$ and $\mathrm{K} 2, S k_{u, \ell}$ assumes rather large negative values at heights $>z / h \approx 2$, suggesting a dominance of upward transport of low-momentum air. Inside the canopy, the streamwise skewness is positive near the crown and becomes negative with increasing depth, which is in agreement with the measurements of Amiro (1990) for a pine forest. The largest peak is obtained with neutral stratification and decreases with the onset of thermal stratification. Field measurements commonly also report such a behaviour (e.g. Baldocchi and Meyers 1988; Leclerc et al. 1991; Launiainen et al. 2007; Dupont and Patton 2012). We can deduce from Fig. 10a that $S k_{u, \ell}$ becomes increasingly negative in the lower canopy with increasing stable stratification, consistent with Leclerc et al. (1991). As Leclerc et al. (1991) point out, negative values of streamwise skewness in the lower canopy usually are connected with an upward transport of momentum, possibly caused by a secondary wind maximum or a layer of unstably stratified air in the trunk space. Since negative streamwise skewness is present in all simulations in the lower canopy with increasingly negative values for increasing stable stratification, this reversal of sign seems to be related to the importance of the secondary wind maximum in our simulations (see Fig. 8b).

The skewness of the vertical velocity component is shown in Fig. 10b and takes positive values above the forest in unstable stratification, which is confirmed by the measurements of Dupont and Patton (2012) and Arnqvist et al. (2014). As pointed out by Dupont and Patton (2012), positive values of $S k_{w, \ell}$ above the forest indicate that updrafts are narrower than the surrounding downdrafts, which is a typical feature of thermal plumes. All other 


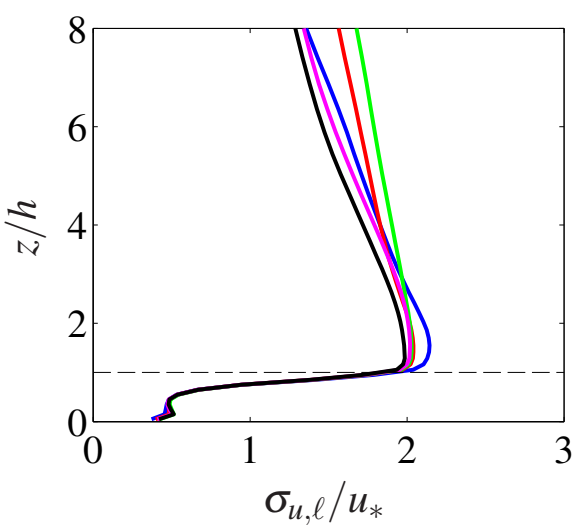

(a)

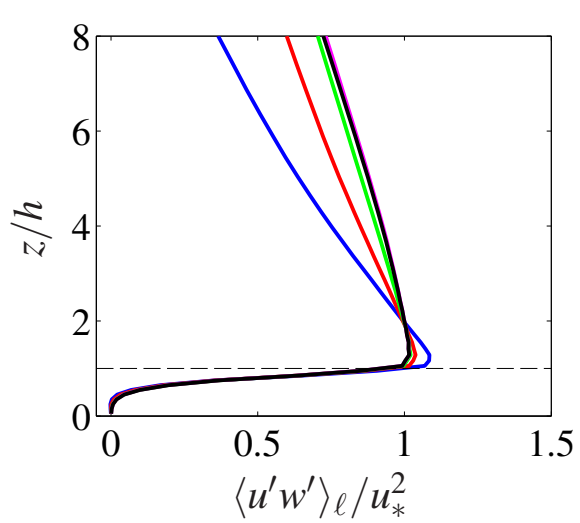

(c)

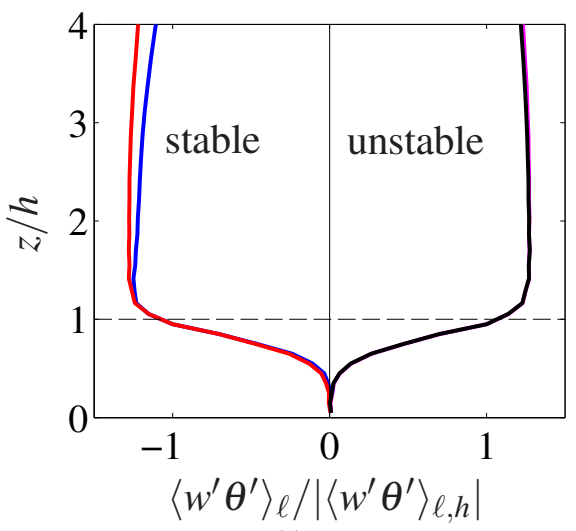

(e)

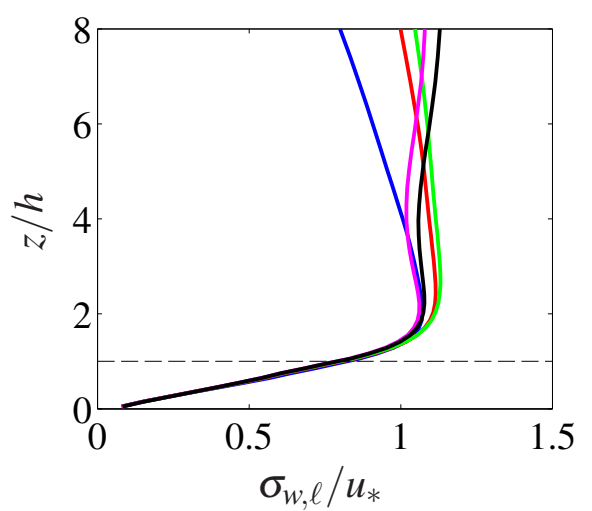

(b)

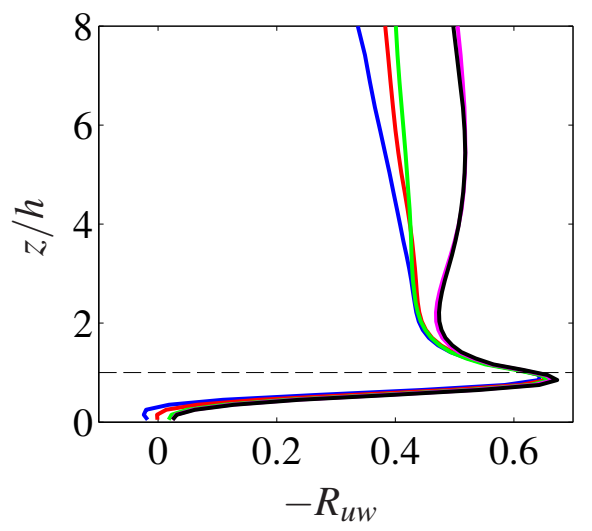

(d)

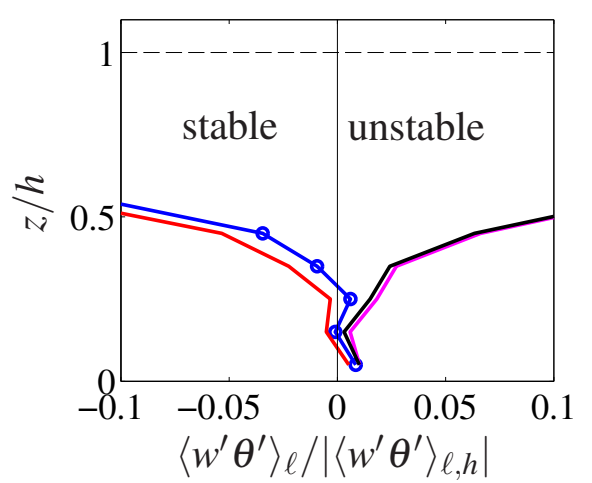

(f)

Fig. 9: Influence of thermal stratification on the standard deviation of the velocity components (a)-(b), the normalized momentum flux (c), the correlation coefficient (d) and the normalized vertical heat flux (e)-(f). $\longrightarrow$ : stable (K5), $\longrightarrow$ : slightly stable (K4), $\longrightarrow$ : neutral (K3), - slightly unstable (K2), $\longrightarrow$ : unstable (K1). The markers in (f) denote cell centres. 
stability classes show values of $S k_{w, \ell}$ near zero above the forest. Within the canopy, the largest magnitudes of vertical skewness are found near the ground for neutral conditions, with smaller magnitudes for both unstable and stable stratification. Leclerc et al. (1991) and Dupont and Patton (2012) report positive vertical skewness inside the forest for very stable stratification $(h / L>0.5)$. Even though we find the least negative values in the most stable simulation (K5) considered, the vertical skewness never changes sign within the forest. It is possible that this is due to too weak stability $(h / L=0.12)$ in case K5.

The kurtosis of the streamwise and vertical velocities is shown in Figs. 10c and 10d. Kurtosis values close to the Gaussian value of $K t_{u, \ell} \approx 3$ are found above the canopy, except for the two unstable cases, showing smaller values up to $z \approx 4 h$. This behaviour is probably due to the overly strong buoyant mixing in these simulations and is not usually observed in the field (Dupont and Patton 2012). The kurtosis of both the streamwise and the vertical components shows that the amplitudes increase slightly with the onset of stable conditions, indicating increasingly intermittent turbulent fluctuations.

Inside the canopy, however, the kurtosis of the streamwise and vertical velocity components decreases with the onset of non-neutral conditions, consistent with Dupont and Patton (2012). Regardless of the thermal stability, the streamwise kurtosis shows a distinct peak in the upper canopy, while in contrast the vertical kurtosis shows the highest values towards the ground.

\subsection{Turbulent kinetic energy budget}

A valuable method for the investigation of the different mechanism involved in generation, dissipation and transport of resolved TKE is to calculate the terms involved in the budget equation for TKE. Budgets of TKE have been subject to extensive investigation, including field measurements (e.g. Leclerc et al. 1990; Meyers and Baldocchi 1991; Zhuang and Amiro 1994), wind-tunnel studies (e.g. Raupach et al. 1986; Brunet et al. 1994; Poggi et al. 2004a; Yue et al. 2008) and numerical studies (e.g. Dwyer et al. 1997; Shen and Leclerc 1997; Yang et al. 2006a; Yue et al. 2008).

Assuming horizontal homogeneity and quasi-steady flow, the TKE budget equation reads (Stull 1988),

$$
\begin{aligned}
0=\frac{\partial\langle K\rangle}{\partial t}= & \underbrace{-\left\langle u^{\prime} w^{\prime}\right\rangle \frac{\partial\langle u\rangle}{\partial z}-\left\langle v^{\prime} w^{\prime}\right\rangle \frac{\partial\langle v\rangle}{\partial z}}_{\mathrm{I}}+\underbrace{\frac{g}{\theta_{0}}\left\langle w^{\prime} \theta^{\prime}\right\rangle \delta_{i 3}}_{\mathrm{II}} \\
& \underbrace{-\frac{1}{\rho} \frac{\partial\left\langle w^{\prime} p^{\prime}\right\rangle}{\partial z} \underbrace{-2 C_{D} a_{f} U\langle K\rangle}_{\mathrm{IV}}}_{\mathrm{III}} \\
& \underbrace{-\frac{\partial\left\langle w^{\prime} K\right\rangle}{\partial z}+\left\langle\left(v+v_{t}\right) \frac{\partial^{2} K}{\partial z^{2}}\right\rangle}_{\mathrm{V}} \underbrace{-\left\langle\left(v+v_{t}\right) \frac{\partial u_{i}^{\prime}}{\partial x_{j}} \frac{\partial u_{i}^{\prime}}{\partial x_{j}}\right\rangle}_{\mathrm{VI}},
\end{aligned}
$$

where $K=\frac{1}{2} u_{i}^{\prime} u_{i}^{\prime}$ is the resolved-scale TKE and the angular brackets denote horizontal and time averaging. Note that the overbars denoting spatial filtering are omitted now for clarity. The time averaging, is performed by averaging over 20 datasets that were obtained with a temporal separation of 250 timesteps (100 s). The terms involved in Eq. 16 are, I) the shear production $\left(P_{s}\right)$, II) the buoyancy production or destruction $\left(P_{b}\right)$, III) the pressure 


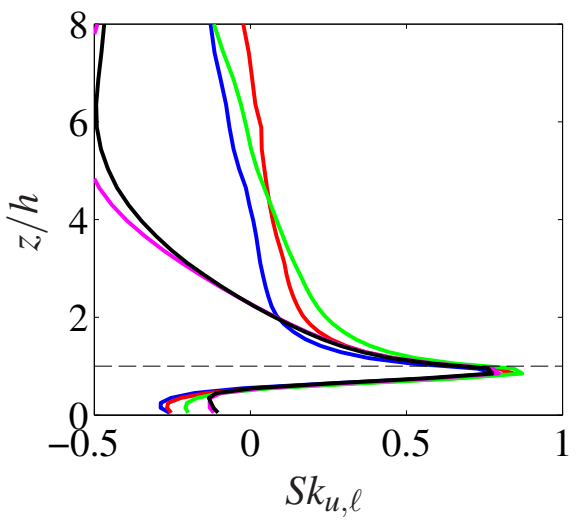

(a)

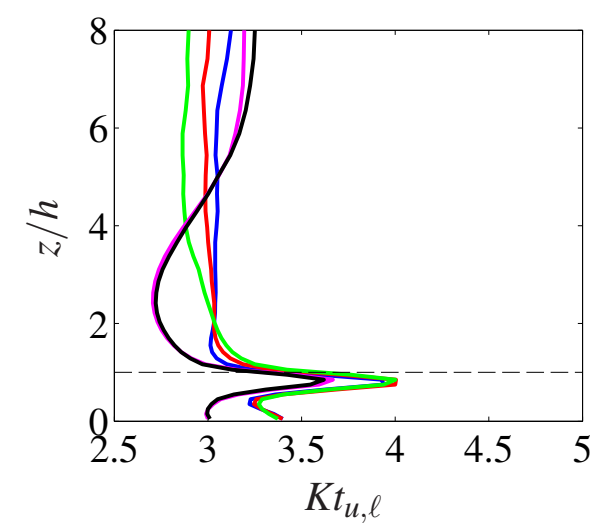

(c)

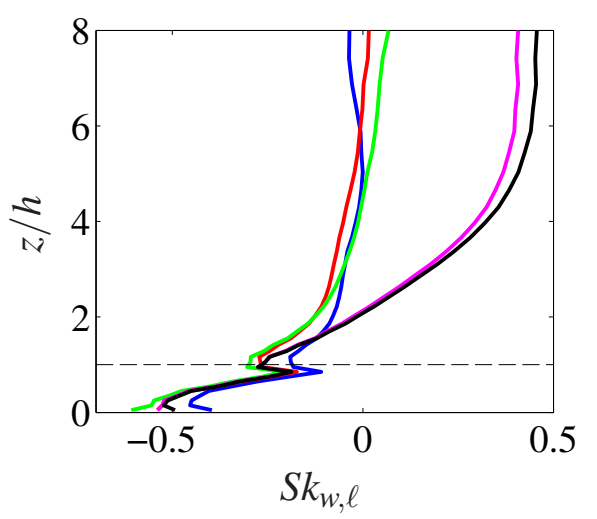

(b)

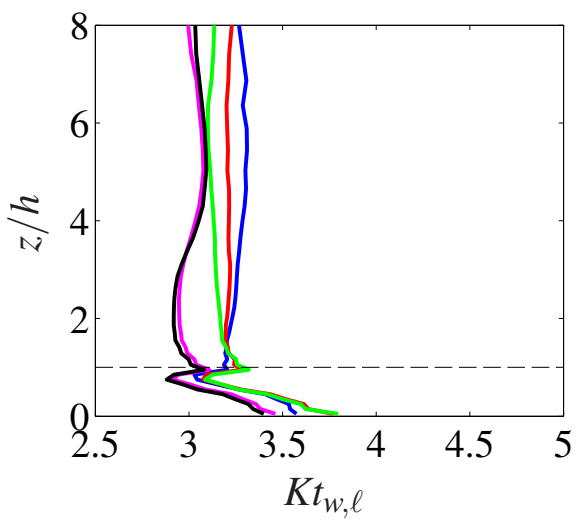

(d)

Fig. 10: Influence of thermal stratification on the skewness (a)-(b) and the kurtosis (c)-(d) of the streamwise and vertical velocity components. $\longrightarrow$ : stable (K5), —: slightly stable (K4), — : neutral (K3), — : slightly unstable (K2), —: unstable (K1).

transport term $\left.\left(T_{p}\right), \mathrm{IV}\right)$ a term accounting for the work done against the canopy $\operatorname{drag}\left(D_{f}\right)$, V) the turbulent transport term $\left(T_{T}\right)$ and VI) the viscous and SGS dissipation $\varepsilon$. However, since $v_{t} \gg v$, the contribution of the viscous dissipation is negligible and the term can be interpreted as the SGS dissipation. According to Dwyer et al. (1997), we include both resolved-scale and SGS turbulent transport in $T_{T}$. In the following, all quantities are made non-dimensional by multiplication with $h / u_{*}^{3}$.

Firstly, we broadly examine the TKE budget for the unstable (K1), neutral (K3) and stable (K5) simulations in Fig. 11. Above the roughness sublayer $(z / h>2)$, an equilibrium of shear production and SGS dissipation $\left(P_{S} \approx \varepsilon\right)$ is usually expected (Townsend 1976). It can be seen that this is roughly true for neutral and stable conditions, but not for unstable stratification, where also turbulent transport plays a significant role. Since shear production vanishes due to small velocity gradients above $z \approx 6 h$, turbulent transport becomes the main contributor of TKE (Garratt 1992, p. 33). Inside the roughness sublayer, the equilibrium as- 
sumption does not hold and the TKE budget is a balance of five different terms. At the top of the canopy, $P_{S}$ exhibits a strong peak associated with the inflection point in the velocity profile (see Fig. 8). The shear production increases with increasing stability, agreeing well with Leclerc et al. (1990). However, these authors further found that in very stable stratification, $P_{S}$ can behave like a weak sink term for TKE in the lower part of the canopy, which is not reproduced here, possibly due to not stable enough stratification. As a result of diminished momentum flux, $P_{S}$ rapidly decreases with depth into the canopy. Dissipation due to canopy drag, $D_{f}$, is the largest sink term throughout the canopy, regardless of the thermal stability, implying that inside the forest, the turbulent motions are predominantly suppressed by canopy drag. All of the above is in general agreement with previously published studies (e.g. Dwyer et al. 1997; Shen and Leclerc 1997; Yang et al. 2006a; Yue et al. 2008). The turbulent transport term is shown in Fig. 12a, and exhibits the behaviour well known

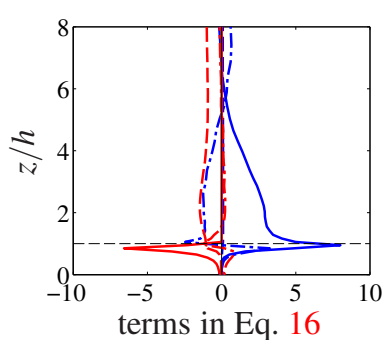

(a)

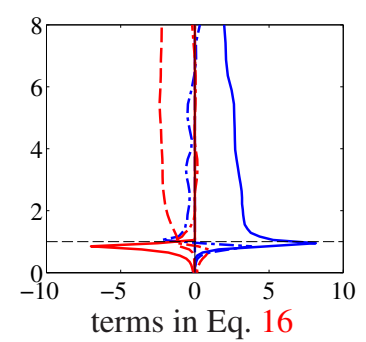

(b)

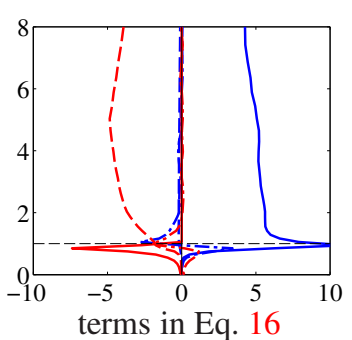

(c)

Fig. 11: Normalized TKE budget for the unstable (a), neutral (b) and stable simulation (c). - : shear production $\left(P_{S}\right), \mathbf{-}$-: buoyancy production $\left(P_{b}\right), \mathbf{-} \cdot \mathbf{-}$ : turbulent transport $\left(T_{T}\right)$,

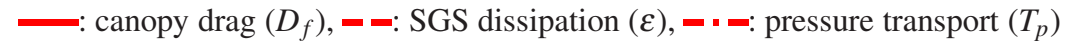

from previous simulations (e.g. Dwyer et al. 1997; Shen and Leclerc 1997), field measurements (Meyers and Baldocchi 1991) and wind-tunnel studies (Raupach et al. 1986; Brunet et al. 1994). Right above the canopy, the turbulent transport shows a strong negative peak and is in fact the most important sink term at $z \approx 1.1 \mathrm{~h}$, while inside the canopy, $T_{T}$ quickly changes sign and acts as a source term for TKE in the upper two thirds of the canopy. Thermal stratification appears to have only a minor effect on the peak magnitudes of $T_{T}$, where the strongest above-canopy sink and in-canopy source are encountered in stable and neutral conditions, respectively. Raupach et al. (1991) pointed out that the importance of turbulent transport inside the canopy should be related to the dominance of sweeps. Thus, the lower magnitude of $T_{T}$ in the forest in stable conditions underlines that sweeps are getting less important in stable conditions. Close to the ground, at $z / h \approx 0.15$, turbulent transport acts as a weak sink for TKE, possibly explained by the lower canopy density in that region, providing for increased turbulence levels near the ground (see Fig. 9a).

Figure 12b displays the pressure transport term, and it can be seen that $T_{p}$ acts similar to $T_{T}$ with a negative and a positive peak right above and inside the canopy $(z \approx 0.75 h)$, respectively. In field measurements, $T_{p}$ is particularly difficult to measure and therefore, there is some debate about its nature. Brunet et al. (1994) derived $T_{p}$ from the difference of other terms and concluded that the pressure transport counteracts the turbulent transport. However, all LES studies agree on pressure transport acting similar to turbulent transport (e.g. 


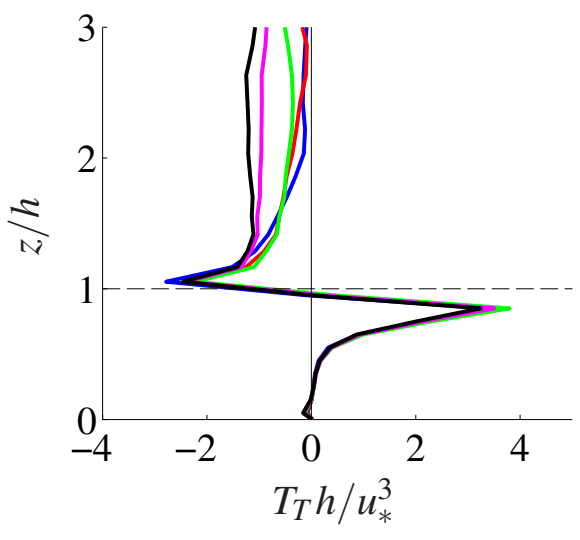

(a)

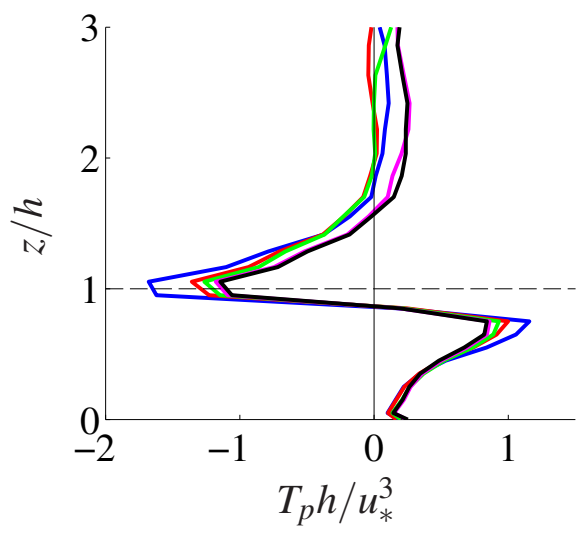

(b)

Fig. 12: Normalized turbulent transport, $T_{T}$, and pressure transport, $T_{p}$ in the canopy region. —: stable (K5), — : slightly stable (K4), — —.: unstable (K1).

Dwyer et al. 1997; Shen and Leclerc 1997; Yang et al. 2006a; Yue et al. 2008). A clear dependence on atmospheric stability can be seen for $T_{p}$, suggesting that pressure transport becomes a more important means of TKE transfer inside the canopy for increasingly stable conditions, probably due to the diminished importance of turbulence. This finding is in line with Shaw and Zhang (1992), who provided evidence for the importance of pressureinduced flow within the canopy. Moreover, it is interesting to note that most of the TKE deep inside the canopy is not locally generated, but rather transferred down with the help of the turbulent transport and pressure transport terms (Raupach et al. 1996).

\section{Summary and conclusions}

A number of large-eddy simulations were performed for the flow over a horizontally homogeneous forest canopy. Six different classes of thermal stability, identified from field measurements and ranging from unstable to very stable conditions, were reproduced numerically. For the first time, also stable stratification was considered in simulations of canopy flows. The simulations were validated against recent field measurements of a pine forest in the south-east of Sweden. Good agreement between measurements and simulations was achieved for the wind speed profile in all, but the most stable case. In particular in unstable and neutral stratification, the simulations showed a large underprediction of the wind turning angle above the canopy. While the vertical momentum flux was generally well predicted, only the streamwise velocity variances agreed with the measurements. The lateral and vertical variances appeared underpredicted for most stability regimes, caused by a general underprediction of resolved turbulent kinetic energy. Using a greater domain size, as well as a finer grid resolution may help to improve that situation. Moreover, the unstable simulations showed clear signs of overmixing due to buoyancy. However, most turbulence features are in, at least, qualitative agreement with published field measurements. 
The $k$-equation SGS model failed for the very stable case, where numerical oscillations appeared in the laminar region above the shallow boundary layer, as a consequence of vanishing turbulent viscosity. In future studies, SGS models more suitable for the stable ABL should be employed. Especially, the so-called scale-dependent dynamic SGS model showed promising performance in stably stratified flow (Kleissl et al. 2006; Stoll and Porté-Agel 2008).

In LES of the unstably stratified ABL, a positive heat flux is applied as a vertically distributed source term in the forest (Shaw and Zhang 1992), motivated by the heating of the forest due to solar radiation. For the sake of simplicity, this situation is reversed in stable stratification. Even though the underlying assumption is violated, this model is able to retain the heat-flux distribution typically observed in forests.

A gradual decrease of the shear length scale, $L_{s} / h$, with increasingly stable stratification (from K1 to K6) showed that stable conditions exhibit stronger wind shear than unstable or neutral conditions. Moreover, the penetration depth of momentum into the canopy is reduced in stable conditions, compared to neutral or unstable stratification, as indicated by an increased displacement height and more rapid momentum flux attenuation with depth into the canopy. Inactive turbulence, in a sense that it does not contribute to vertical momentum transfer, could be observed deep inside the canopy, and was found to be most prominent in unstable conditions. Evidence was found for a layer of unstably stratified air in the canopy trunk space under stable stratification. A secondary wind speed maximum was observed near the ground, probably due to the relatively lower forest density in that region. The importance of the secondary wind speed maximum was increased in stable stratification.

Generally speaking, the simulated skewness profiles exhibited the features typical of canopy flows. The highest in-canopy skewness magnitudes was observed for neutral conditions, while both stable and unstable stratification lead to slightly smaller magnitudes. Negative values of streamwise skewness were found deep inside the canopy and are likely connected to the observed secondary wind maximum. For unstable stratification, strong negative streamwise and positive vertical skewnesses imply that these cases are entirely governed by thermal updrafts due to buoyancy. Strongly positive vertical skewness in these cases implies that updrafts are narrower than the surrounding downdrafts. With the onset of stable conditions, the kurtosis values suggested increasingly intermittent turbulent fluctuations.

In general, the TKE budget shows the features typically observed for canopy flows. It was found that the local equilibrium assumption holds for heights greater than the roughness sublayer in neutral and stable conditions. In unstable stratification, the pressure transport term takes over the role as the dominant source term at greater heights, due to vanishing velocity gradients and thus vanishing shear production. Within the roughness sublayer and inside the canopy, the local equilibrium assumption does not hold. Shear production increases with increasing stability, simply as a consequence of the increased wind shear. No clear influence of stability on the turbulent transport was found, while the pressure transport was more influenced by thermal stratification. With increasingly stable conditions, pressure transport seems to play an increasingly important role in supplying the canopy region with TKE.

Acknowledgements The authors are thankful to Johan Arnqvist (Uppsala University), Ebba Dellwik (DTU) and Hans Bergström (Uppsala University) for providing the field measurement data.

This project is financed through the Swedish Wind Power Technology Centre (SWPTC). SWPTC is a research centre for the design of wind turbines. The purpose of the centre is to support Swedish industry with knowledge of design techniques as well as maintenance in the field of wind power. The Centre is funded by the Swedish Energy Agency, Chalmers University of Technology as well as academic and industrial partners. 


\section{References}

Allen Jr L. H. (1968) Turbulence and wind speed spectra within a Japanese larch plantation. J Appl Meteorol 7(1):73-78

Amiro B. D. (1990) Comparison of turbulence statistics within three boreal forest canopies. Boundary-Layer Meteorol 51(1-2):99-121

Arnqvist J., Dellwik E., Segalini A., Bergström H. (2014) Wind statistics from a forested landscape. to appear in Boundary-Layer Meteorol

Bailey B. N., Stoll R. (2013) Turbulence in sparse, organized vegetative canopies: a largeeddy simulation study. Boundary-Layer Meteorol 147(3):369-400

Baldocchi D. D., Meyers T. P. (1988) Turbulence structure in a deciduous forest. Boundary-Layer Meteorol 43(4):345-364

Basu S., Porté-Agel F. (2006) Large-Eddy Simulation of Stably Stratified Atmospheric Boundary Layer Turbulence: A Scale-Dependent Dynamic Modeling Approach. J Atmos Sci 63(8):2074-2091

Bergström H., Alfredsson H., Arnqvist J., Carlén I., Dellwik E., Fransson J., Ganander H., Mohr M., Segalini A., Söderberg S. (2013) Wind Power in Forests: Wind and Effects on Loads. Vindforsk Rapport 167 pp.

Bhushan S., Warsi Z. U. A. (2005) Large eddy simulation of turbulent channel flow using an algebraic model. Int J Numer Meth Fluids 49(5):489-519

Bhushan S., Warsi Z. U. A., Walters K. D. (2006) Modeling of energy backscatter via an algebraic subgrid-stress model. AIAA J 44(4):837-847

Bohrer G., Katul G. G., Walko R. L., Avissar R. (2009) Exploring the effects of microscale structural heterogeneity of forest canopies using large-eddy simulations. BoundaryLayer Meteorol 132(3):351-382

Breuer L., Eckhardt K., Frede H.-G. (2003) Plant Parameter Values for Models in Temperate Climates. Ecol Model 169(2):237-293

Brunet Y., Irvine M. R. (2000) The control of coherent eddies in vegetation canopies: streamwise structure spacing, canopy shear scale and atmospheric stability. Boundary-Layer Meteorol 94(1):139-163

Brunet Y., Finnigan J. J., Raupach M. R. (1994) A wind tunnel study of air flow in waving wheat: single-point velocity statistics. Boundary-Layer Meteorol 70(1-2):95-132

Cassiani M., Katul G. G., Albertson J. D. (2008) The effects of canopy leaf area index on airflow across forest edges: large-eddy simulation and analytical results. BoundaryLayer Meteorol 126(3):433-460

Cava D., Katul G. G., Scrimieri A., Poggi D., Cescatti A., Giostra U. (2006) Buoyancy and the sensible heat flux budget within dense canopies. Boundary-Layer Meteorol 118(1):217-240

Chahine A., Dupont S., Sinfort C., Brunet Y. (2014) Wind-Flow Dynamics Over a Vineyard. Boundary-Layer Meteorol 151(3):557-577

Chatziefstratiou E. K., Velissariou V., Bohrer G. (2014) Resolving the Effects of Aperture and Volume Restriction of the Flow by Semi-Porous Barriers Using Large-Eddy Simulations. Boundary-Layer Meteorol 152(3):329-348

Chougule A., Mann J., Segalini A., Dellwik E. (2015) Spectral tensor parameters for wind turbine load modeling from forested and agricultural landscapes. Wind Energy 18(3):469-481

Cionco R. M. (1972) Intensity of turbulence within canopies with simple and complex roughness elements. Boundary-Layer Meteorol 2(4):453-465

Davidson L. (2009) Hybrid LES-RANS: back scatter from a scale-similarity model used 
as forcing. Phil Trans R Soc A 367(1899):2905-2915

Deardorff J. W. (1980) Stratocumulus-capped mixed layers derived from a threedimensional model. Boundary-Layer Meteorol 18(4):495-527

Dupont S., Brunet Y. (2008a) Edge flow and canopy structure: A large-eddy simulation study. Boundary-Layer Meteorol 126(1):51-71

Dupont S., Brunet Y. (2008b) Influence of foliar density profile on canopy flow: A largeeddy simulation study. Agric For Meteorol 148(6):976-990

Dupont S., Brunet Y. (2009) Coherent structures in canopy edge flow: A large-eddy simulation study. J Fluid Mech 630:93-128

Dupont S., Patton E. G. (2012) Influence of stability and seasonal canopy changes on micrometeorology within and above an orchard canopy: The CHATS experiment. Agric For Meteorol 157:11-29

Dupont S., Bonnefond J. M., Irvine M. R., Lamaud E., Brunet Y. (2011) Long-distance edge effects in a pine forest with a deep and sparse trunk space: In situ and numerical experiments. Agric For Meteorol 151(3):328-344

Dwyer M. J., Patton E. G., Shaw R. H. (1997) Turbulent kinetic energy budgets from a large-eddy simulation of airflow above and within a forest canopy. Boundary-Layer Meteorol 84(1):23-43

Endalew A. M., Hertog M., Gebrehiwot M. G., Baelmans M., Ramon H., Nicolaï B. M., Verboven P. (2009) Modelling airflow within model plant canopies using an integrated approach. Comput Electron Agric 66(1):9-24

Finnigan J. (1979) Turbulence in waving wheat II Structure of momentum transfer. Boundary-Layer Meteorol 16:213-236

Finnigan J. J. (2000) Turbulence in plant canopies. Annual Review of Fluid Mechanics 32(1):519-571

Finnigan J. J., Shaw R. H., Patton E. G. (2009) Turbulence structure above a vegetation canopy. J Fluid Mech 637:387-424

Garratt J. R. (1992) The atmospheric boundary layer. Cambridge University Press, UK, $316 \mathrm{pp}$.

Högström U., Bergström H., Smedman A. S., Halldin S., Lindroth A. (1989) Turbulent exchange above a pine forest, I: Fluxes and gradients. Boundary-Layer Meteorol 49(12):197-217

Hu X., Lee X., Stevens D. E., Smith R. B. (2002) A Numerical Study of Nocturnal Wavelike Motion in Forests. Boundary-Layer Meteorol 102(2):199-223

Huang J., Cassiani M., Albertson J. D. (2009) The effects of vegetation density on coherent turbulent structures within the canopy sublayer: a large-eddy simulation study. Boundary-Layer Meteorol 133(2):253-275

Jiménez M. A., Cuxart J. (2005) Large-eddy simulations of the stable boundary layer using the standard Kolmogorov theory: Range of applicability. Boundary-Layer Meteorol 115(2):241-261

Kaimal J. C., Finnigan J. J. (1994) Atmospheric boundary layer flows: their structure and measurement. Oxford University Press, 289 pp.

Kanda M., Hino M. (1994) Organized structures in developing turbulent flow within and above a plant canopy, using a large eddy simulation. Boundary-Layer Meteorol 68(3):237-257

Kleissl J., Kumar V., Meneveau C., Parlange M. B. (2006) Numerical study of dynamic Smagorinsky models in large-eddy simulation of the atmospheric boundary layer: Validation in stable and unstable conditions. Water Resour Res 42(6)

Kruijt B., Malhi Y., Lloyd J., Norbre A. D., Miranda A. C., Pereira M. G. P., Culf 
A., Grace J. (2000) Turbulence statistics above and within two Amazon rain forest canopies. Boundary-Layer Meteorol 94(2):297-331

Lalic B., Mihailovic D. T. (2004) An Empirical Relation Describing Leaf-Area Density inside the Forest for Environmental Modeling. J Appl Meteorol 43(4)

Launiainen S., Vesala T., Mölder M., Mammarella I., Smolander S., Rannik Ü., Kolari P., Hari P., Lindroth A., Katul G. G. (2007) Vertical variability and effect of stability on turbulence characteristics down to the floor of a pine forest. Tellus B 59(5):919-936

Leclerc M. Y., Beissner K. C., Shaw R. H., Den Hartog G., Neumann H. H. (1990) The influence of atmospheric stability on the budgets of the Reynolds stress and turbulent kinetic energy within and above a deciduous forest. J Appl Meteorol 29(9):916-933

Leclerc M. Y., Beissner K. C., Shaw R. H., Den Hartog G., Neumann H. H. (1991) The influence of buoyancy on third-order turbulent velocity statistics within a deciduous forest. Boundary-Layer Meteorol 55(1-2):109-123

Lee X., Black T. A. (1993) Atmospheric turbulence within and above a Douglas-fir stand. Part I: statistical properties of the velocity field. Boundary-Layer Meteorol 64(12):149-174

Meyers T. P., Baldocchi D. D. (1991) The budgets of turbulent kinetic energy and Reynolds stress within and above a deciduous forest. Agric For Meteorol 53(3):207222

Moeng C. H. (1984) A Large-Eddy Simulation Model for the Study of Planetary Boundary-Layer Turbulence. J Atmos Sci 41(13):2052-2062

Nebenführ B., Davidson L. (2014) Influence of a forest canopy on the neutral atmospheric boudary layer - A LES study. In: ETMM10: 10th International ERCOFTAC Symposium on Turbulence Modelling and Measurements, Marbella, Spain, 17-19 September, 2014

Nebenführ B., Carlén I., Caracoglia L., Davidson L. (2014) Development of a reducedorder model for wind turbine response to atmospheric turbulence in forest regions. In: Proceedings of 6th International Symposium on Computational Wind Engineering, Hamburg, Germany, 8-12 June, 2014

Novak M. D., Warland J. S., Orchansky A. L., Ketler R., Green S. (2000) Wind tunnel and field measurements of turbulent flow in forests. Part I: uniformly thinned stands. Boundary-Layer Meteorol 95(3):457-495

Poggi D., Katul G. G., Albertson J. D. (2004a) Momentum transfer and turbulent kinetic energy budgets within a dense model canopy. Boundary-Layer Meteorol 111(3):589614

Poggi D., Porporato A., Ridolfi L., Albertson J. D., Katul G. G. (2004b) The effect of vegetation density on canopy sub-layer turbulence. Boundary-Layer Meteorol 111(3):565-587

Porté-Agel F., Meneveau C., Parlange M. B. (2000) A scale-dependent dynamic model for large-eddy simulation: application to a neutral atmospheric boundary layer. J Fluid Mech 415:261-284

Raupach M. R., Coppin P. A., Legg B. J. (1986) Experiments on scalar dispersion within a model plant canopy part I: The turbulence structure. Boundary-Layer Meteorol 35(12):21-52

Raupach M. R., Antonia R. A., Rajagopalan S. (1991) Rough-wall turbulent boundary layers. Appl Mech Rev 44(1):1-25

Raupach M. R., Finnigan J. J., Brunet Y. (1996) Coherent eddies and turbulence in vegetation canopies: the mixing-layer analogy. Boundary-Layer Meteorol 78(3-4):351-382

Schlegel F., Stiller J., Bienert A., Maas H.-G., Queck R., Bernhofer C. (2012) Large- 
eddy simulation of inhomogeneous canopy flows using high resolution terrestrial laser scanning data. Boundary-Layer Meteorol 142(2):223-243

Schröttle J., Dörnbrack A. (2013) Turbulence structure in a diabatically heated forest canopy composed of fractal Pythagoras trees. Theor Comp Fluid Dyn 27(3-4):337359

Segalini A., Fransson J. H. M., Alfredsson P. H. (2013) Scaling Laws in Canopy Flows: A Wind-Tunnel Analysis. Boundary-Layer Meteorol 148(2):269-283

Shaw R. H. (1977) Secondary wind speed maxima inside plant canopies. J Appl Meteorol 16(5):514-521

Shaw R. H., Patton E. G. (2003) Canopy element influences on resolved-and subgrid-scale energy within a large-eddy simulation. Agric For Meteorol 115(1):5-17

Shaw R. H., Schumann U. (1992) Large-Eddy Simulation of Turbulent Flow above and within a Forest. Boundary-Layer Meteorol 61(1-2):47-64

Shaw R. H., Zhang X. J. (1992) Evidence of pressure-forced turbulent flow in a forest. Boundary-Layer Meteorol 58(3):273-288

Shaw R. H., Den Hartog G., Neumann H. H. (1988) Influence of foliar density and thermal stability on profiles of Reynolds stress and turbulence intensity in a deciduous forest. Boundary-Layer Meteorol 45(4):391-409

Shen S., Leclerc M. Y. (1997) Modelling the turbulence structure in the canopy layer. Agric For Meteorol 87(1):3-25

Stoll R., Porté-Agel F. (2008) Large-eddy simulation of the stable atmospheric boundary layer using dynamic models with different averaging schemes. Boundary-Layer Meteorol 126(1):1-28

Stull R. B. (1988) An Introduction to Boundary Layer Meteorology. Kluwer Academic Pub, 666 pp.

Su H. B., Shaw R. H., Paw K. T., Moeng C. H., Sullivan P. P. (1998) Turbulent statistics of neutrally stratified flow within and above a sparse forest from large-eddy simulation and field observations. Boundary-Layer Meteorol 88(3):363-397

Su H. B., Schmid H. P., Vogel C. S., Curtis P. S. (2008) Effects of canopy morphology and thermal stability on mean flow and turbulence statistics observed inside a mixed hardwood forest. Agric For Meteorol 148(6):862-882

Townsend A. A. (1976) The structure of turbulent shear flow. Cambridge University Press, UK, $429 \mathrm{pp}$.

Villani M. G., Schmid H. P., Su H. B., Hutton J. L., Vogel C. S. (2003) Turbulence statistics measurements in a northern hardwood forest. Boundary-Layer Meteorol 108(3):343-364

Watanabe T. (2004) Large-eddy simulation of coherent turbulence structures associated with scalar ramps over plant canopies. Boundary-Layer Meteorol 112(2):307-341

Yang B., Morse A. P., Shaw K. T. R H Paw U (2006a) Large-eddy simulation of turbulent flow across a forest edge. Part II: momentum and turbulent kinetic energy budgets. Boundary-Layer Meteorol 121(3):433-457

Yang B., Shaw R. H., Paw U K. T. (2006b) Wind loading on trees across a forest edge: a large eddy simulation. Agric For Meteorol 141(2):133-146

Yue W., Meneveau C., Parlange M. B., Zhu W., van Hout R., Katz J. (2007a) A comparative quadrant analysis of turbulence in a plant canopy. Water Resour Res 43(5), DOI 10.1029/2006WR005583

Yue W., Parlange M. B., Meneveau C., Zhu W., van Hout R., Katz J. (2007b) Large-eddy simulation of plant canopy flows using plant-scale representation. Boundary-Layer Meteorol 124(2):183-203 
Yue W., Meneveau C., Parlange M. B., Zhu W., Kang H. S., Katz J. (2008) Turbulent kinetic energy budgets in a model canopy: comparisons between LES and wind-tunnel experiments. Environ Fluid Mech 8(1):73-95

Zhuang Y., Amiro B. D. (1994) Pressure fluctuations during coherent motions and their effects on the budgets of turbulent kinetic energy and momentum flux within a forest canopy. J Appl Meteorol 33(6):704-711 